\title{
Socioeconomic inequalities in hypertension in Kenya: a decomposition analysis of 2015 Kenya STEPwise survey on non- communicable diseases risk factors
}

\author{
Samwel Maina Gatimu ${ }^{1 *}$ and Thomas Wiswa John²
}

\begin{abstract}
Background: One in four Kenyans aged 18-69 years have raised blood pressure. Despite this high prevalence of hypertension and known association between socioeconomic status and hypertension, there is limited understanding of factors explaining inequalities in raised blood pressure in Kenya. Hence, we quantified the socioeconomic inequality in hypertension in Kenya and decomposed the determinants contributing to such inequality.

Methods: We used data from the 2015 Kenya STEPwise survey for non-communicable diseases risk factors. We included 4422 respondents aged 18-69 years. We estimated the socioeconomic inequality using the concentration index (C) and decomposed the $\mathrm{C}$ using Wagstaff decomposition analysis.

Results: The overall concentration index of hypertension in Kenya was -0.08 (95\% Cl: $-0.14,-0.02 ; p=0.005)$, showing socioeconomic inequalities in hypertension disfavouring the poor population. About half (47.1\%) of the pro-rich inequalities in hypertension was explained by body mass index while $26.7 \%$ by socioeconomic factors (wealth index (10.4\%), education (9.3\%) and paid employment (7.0\%)) and $17.6 \%$ by sociodemographic factors (female gender (10.5\%), age (4.3\%) and marital status (0.6\%)). Regional differences explained $7.1 \%$ of the estimated inequality with the Central region alone explaining $6.0 \%$ of the observed inequality. Our model explained $99.7 \%$ of the estimated socioeconomic inequality in hypertension in Kenya with a small non-explained part of the inequality $(-0.0002)$.

Conclusion: The present study shows substantial socioeconomic inequalities in hypertension in Kenya, mainly explained by metabolic risk factors (body mass index), individual health behaviours, and socioeconomic factors. Kenya needs gender- and equity-focused interventions to curb the rising burden of hypertension and inequalities in hypertension.
\end{abstract}

Keywords: Socioeconomic inequality, Hypertension, Kenya, NCDs, Inequalities, STEPwise, Risk factors

\footnotetext{
* Correspondence: gatimu.maina@gmail.com

${ }^{1}$ School of Economics, University of Nairobi, Nairobi, Kenya

Full list of author information is available at the end of the article
}

(C) The Author(s). 2020 Open Access This article is licensed under a Creative Commons Attribution 4.0 International License, which permits use, sharing, adaptation, distribution and reproduction in any medium or format, as long as you give appropriate credit to the original author(s) and the source, provide a link to the Creative Commons licence, and indicate if changes were made. The images or other third party material in this article are included in the article's Creative Commons licence, unless indicated otherwise in a credit line to the material. If material is not included in the article's Creative Commons licence and your intended use is not permitted by statutory regulation or exceeds the permitted use, you will need to obtain permission directly from the copyright holder. To view a copy of this licence, visit http://creativecommons.org/licenses/by/4.0/ The Creative Commons Public Domain Dedication waiver (http://creativecommons.org/publicdomain/zero/1.0/) applies to the data made available in this article, unless otherwise stated in a credit line to the data. 


\section{Background}

Low- and middle-income countries (LMICs) including Kenya bear the largest burden of non-communicable diseases (NCDs) [1]. High blood pressure is one of the risk factors of NCDs [2]. It affects about a third of the global population and causes an estimated 7.6 million premature deaths [1]. In Kenya, a quarter of the population aged 18-69 years is estimated to be hypertensive [3] and a half pre-hypertensive [4]. The prevalence of hypertension is higher among women and urban residents than among men and rural residents [5]. Hypertensive disease is associated with a high burden of out of pocket expenditure to patients and family with an annual cost of US\$477 and contributing to 59\% of the catastrophic healthcare costs [6].

Hypertension is associated with socioeconomic status [7-11]. Low socioeconomic status is associated with a high prevalence of hypertension, and untreated and uncontrolled hypertension in LMICs [7-11]. However, this is not a consistent finding. For example, in Kenya, a study among urban adults found a high prevalence of hypertension among the richest individuals [12] while others studies have shown a high prevalence among the poor individuals [10, 11]. A different study explaining the association between socioeconomic position and hypertension in Kenya found that education is not associated with hypertension but material resources were positively associated but not mediated by smoking and alcohol [13].

Furthermore, studies on socioeconomic inequalities in hypertension have also shown that both pro-poor and pro-rich inequalities exist in hypertension $[9,14,15]$. In Kenya, however, despite a high prevalence of hypertension, studies have shown the existence of social gradient in hypertension among different populations $[5,12,16]$ but the extent and pattern of inequalities and potential factors explaining the socioeconomic inequalities in hypertension across wealth distribution are not well understood. Understanding inequalities in hypertension is key to inform interventions to prevent hypertension and reduce premature mortality from hypertension by $25 \%$ by 2025 in line with the global [2] and national targets [17]. Therefore, this study quantified the socioeconomic inequality in hypertension in Kenya and decomposed the determinants contributing to such socioeconomic inequality.

\section{Methods}

\section{Data source and study population}

The study used data from the nationwide 2015 Kenya STEPwise survey for non-communicable diseases and injury risk factors among adults aged 18-69 years in Kenya [3]. The survey used a three-stage cluster sample design: selection of 200 equally distributed urban and rural areas clusters, 30 sampled households from the selected clusters and random sampling of one member from all the listed households' members in each household. The STEPwise survey targeted population based on age-sex group, and involved individuals aged 18-69 years [3]. Out of the 4654 households that gave consent, 4500 individuals consented to participate in the survey yielding a $95 \%$ response rate. Structured questionnaires based on WHO STEPwise approach to chronic disease risk factors-demographic and behavioural information (Step 1), anthropometric (Step 2) and biochemical measurements (Step 3)-was used [3]. Personal digital assistant loaded with the eSTEPS questionnaire were used by the trained data collectors to record data. Various quality assurance measures were put in place including regular checks of the collected data for consistency by a quality assurance team. The Kenya Medical Research Institute Ethics Review Committee approved the survey and all eligible participants gave written informed consent [3]. The deidentified data used in this study were accessed from the Kenya National Bureau of Statistics based on a data access agreement [18]. More details of the survey are published elsewhere [3].

\section{Measures \\ Outcome variable}

Hypertension, our main outcome variable was defined as "a systolic blood pressure of $\geq 140 \mathrm{mmHg}$ and/or diastolic blood pressure of $\geq 90 \mathrm{mmHg}$ on two separate occasions or self-reported use of blood pressure medication and/or previous diagnosis by a healthcare provider" $[19,20]$. A binary variable was generated where 0 was normal while 1 was hypertension.

\section{Socioeconomic measure}

Wealth index was used as the measure of socioeconomic position and living standards of the respondents. The wealth index was computed based on the data on household assets using principal component analysis (PCA) [21]. PCA is the standard method to calculate wealth index used in most demographic and health surveys [22, 23]. Key household assets variables assessing ownership of infrastructures and amenities such as source of drinking water, type of toilet, type of house's floor, walls and roof, cooking fuels and availability of electricity were included in the analysis (Supplementary Table 1) [3, 22, 23]. An index was created based on the sum of all weights of included variables, which were generated by PCA after testing and fulfilling all the three assumption (Bartlett's test, Kaiser-Meyer-Olkin measure of sampling adequacy and determinants of matrix correlation) [21, 24]. The resulting continuous-scale wealth index was later categorised into five quintiles (1st quantile - 
poorest, 2nd quantile - poorer, 3rd quantile - middle, 4th quantile - richer and 5th quantile - richest) [24].

\section{Social determinants of hypertension}

The social determinants of hypertension included demographic (age, sex, marital status), socioeconomic (education, occupation, wealth index), anthropometric (body mass index), health behaviours (physical activity, current smoking use, current alcohol use, and fruits and vegetable intake) and community (region and residence) variables (Table 1).

\section{Statistical analysis}

Sample characteristics and prevalence of hypertension were described using frequencies and percentages. Stata 13.1 was used to perform all statistical analyses that were adjusted for the stratified sampling design of the survey.

Socioeconomic inequalities in hypertension in Kenya was quantified using concentration index (C) and depicted using concentration curves. $\mathrm{C}$ is a 'measure of inequality in the distribution of health outcome across the wealth distribution', reflects the experience of the population as the whole and is sensitive to the change in the distribution of the population across socialeconomic groups and can be decomposed [37]. $\mathrm{C}$ ranges from -1 and +1 and $C=0$ shows perfect equality while $\mathrm{C}<0$ shows hypertension is disproportionately concentrated among the poor (pro-rich inequality). It was computed based on the proportion of hypertension by the ranked wealth distribution as follows [37]:

$$
\mathrm{C}=\frac{2}{n \mu} \sum_{i=1}^{n} h_{i} R_{i}-1
$$

where $n$ is the number of people, $\mu$ is the overall mean/ proportion of $h ; h_{i}$ is hypertension in $i^{t h}$ person; $R_{i}$ is the $i^{t h}$ person ranked by wealth index from the poorest to richest [37]. Hypertension is a binary variable, and the $\mathrm{C}$ was normalised by dividing the $\mathrm{C}$ by $1-\boldsymbol{\mu}[38,39]$. We used the Wagstaff-type decomposition analysis of the concentration index [40] to examine the contribution of social determinants of inequality in hypertension. The method has been internationally accepted and has widely been used [41-45] to decompose inequalities across the full distribution of wealth index rather than between the richest and the poorest [37]. It allows for the overall concentration index to be decomposed into contributions of social determinants of health, in which each social determinant's contribution is obtained by multiplying the sensitivity of the outcome variable with respect to that determinant and the degree of wealthrelated inequality in that factor [37]. It also allows decomposition of the changes in the elasticities of health outcome with respect to these social determinants [37].

To decompose, we first considered the linear additive regression model for the outcome variable $(y)$ of an individual $i$ as follow:

$$
\mathrm{y}_{i}=a+\Sigma \mathrm{k} \beta_{\mathrm{k}} \mathrm{x}_{\mathrm{ki}}+\varepsilon_{i}
$$

where the concentration index of health outcome (y) can be written as:

\begin{tabular}{|c|c|c|}
\hline Variable & Operational definition & Source \\
\hline Age in years & Age of the respondents at the time of the interview was categorised into $18-29 ; 30-39 ; 40-49 ; 50+$ years & [25-28] \\
\hline Sex & Male or female & [25-28] \\
\hline Marital status & In-a-union (married or cohabiting); Not-in-a-union (Never married, divorced, separated, or widowed) & {$[5,12,25]$} \\
\hline Education levels & No formal; primary incomplete; primary complete; secondary+ & {$[12,25,29]$} \\
\hline Residence & Urban or rural areas & {$[5,25]$} \\
\hline Region & Nairobi, Central, Eastern, Western, Nyanza, Coast, Rift Valley, North Eastern & [25] \\
\hline Occupation & Unemployed, self-employed, paid employment & {$[12,25,29]$} \\
\hline $\begin{array}{l}\text { Physical activity } \\
\text { levels }\end{array}$ & $\begin{array}{l}\text { Data collected based on the WHO Global Physical Activity questionnaire (GPAQ) was analysed according to the } \\
\text { GPAQ analysis guide [30] and classified into: low (<600 metabolic equivalent of task, METS, minutes per week), } \\
\text { moderate (600-1500), and high ( }>1500 \text { METS minutes per week) }\end{array}$ & {$[5,12,25]$} \\
\hline Current smoker & Current use of tobacco, tobacco products and smokeless cigarette was classified as Yes or No & $\begin{array}{l}{[14,25,31,} \\
32]\end{array}$ \\
\hline $\begin{array}{l}\text { Current alcohol } \\
\text { use }\end{array}$ & Current use of any type of alcohol was classified as Yes or No & {$[14,25,33]$} \\
\hline $\begin{array}{l}\text { Fruits \& vegetable } \\
\text { intake }\end{array}$ & Sufficient ( $\geq 5$ servings); insufficient ( $<5$ servings) & {$[25,27]$} \\
\hline Body mass index & Undernutrition $\left(\leq 18.5 \mathrm{~kg} / \mathrm{m}^{2}\right)$, Normal $\left(18.5-24.9 \mathrm{~kg} / \mathrm{m}^{2}\right)$, Overweight $\left(\geq 25-29.9 \mathrm{~kg} / \mathrm{m}^{2}\right)$, Obese $\left(\geq 30 \mathrm{~kg} / \mathrm{m}^{2}\right)$ & $\begin{array}{l}{[25,28,} \\
34-36]\end{array}$ \\
\hline
\end{tabular}

Table 1 Social determinants of hypertension 


$$
\mathrm{C}_{\text {Normalized }}=\frac{\mathrm{C}}{1-\mu}=\frac{\sum \mathrm{k}\left(\frac{\beta_{\mathrm{k}} \overline{\mathrm{x}}_{\mathrm{k}}}{\mu}\right) \mathrm{C}_{\mathrm{k}}}{1-\mu}+\frac{\mathrm{GC} \varepsilon / \mu}{1-\mu}
$$

where $\mu$ is the mean of hypertension, $\bar{x}_{k}$ is the mean of $x k, C_{k}$ is the concentration index of $x k$, and GCE (residual) is the generalized concentration index for the error term $(\varepsilon)$. C, therefore, is the sum of the two components - the concentration index of the explanatory variables weighted by the elasticity of $y\left(\beta_{k} \bar{x}_{k} / \mu\right)$ which is the explained part and residual part $(\mathrm{GC} \varepsilon / \mu)$ which is the unexplained part [37]. Hypertension, the outcome variable, is non-linear hence a non-linear Probit model was used to estimate the marginal effects $\left(\beta_{k}\right)$ of each determinant [37]. The marginal effects were used to calculate the contribution of $k$ determinants. A negative absolute contribution was interpreted as supporting effect of inequality that favours the rich, to the disadvantage of poor and vice versa. The absolute contributions were adjusted by dividing the absolute contribution of each determinant by the total explained part that make contributions to the same direction of the concentration index.

\section{Results}

\section{Sample characteristics}

Out of the 4500 eligible participants, 4422 respondents were included in the analysis after excluding 15 respondents aged below 18 years or above 69 years and 63 who had missing or incorrect data on blood pressure. A majority of study participants were female (51.4\%), aged $18-29$ years $(46.3 \%)$, lived in rural areas $(61.4 \%)$, in-aunion (65.5\%) and unemployed (40.2\%). A quarter of the respondents $(25.3 \%)$ currently used alcohol, $12.5 \%$ were current smokers, $10.8 \%$ had low physical activity and $11.2 \%$ were obese. Table 2 outlines the respondents' characteristics and the prevalence of hypertension according to the sociodemographic, socioeconomic, behavioural, and anthropometric characteristics.

\section{Prevalence of hypertension}

The overall weighted prevalence of hypertension was $25.8 \%$ (95\% CI: $23.4-28.3 \%$ ) with a higher prevalence among men than women $(28.1 \%$ vs $23.6 \%)$. The prevalence of hypertension was higher among those who were $50+$ years $(52.8 \%)$, paid employment $(31.8 \%)$, obese (45.8\%) and overweight (33.4\%) and from the central region (38.5\%). The prevalence of hypertension was also higher among the poorest (28.2\%) and poorer (29.1\%) compared to the richest (20.1\%) but did not show a clear wealth-related gradient (Table 2).

\section{Socioeconomic inequality in hypertension}

Figures 1 and 2 shows that the concentration curve lay above the line of equality indicating a pro-rich inequality in hypertension disfavouring the poor, with an overall concentration index of hypertension of -0.08 (95\% CI: $-0.14,-0.02 ; p=0.005)$. The social determinants included in our model explained $99.7 \%$ of the estimated socioeconomic inequality in hypertension in Kenya with a small non-explained part of the inequality $(-0.0002)$.

Table 3 presents results of the decomposition analysis that revealed that about half $(47.1 \%)$ of the pro-rich inequalities in hypertension is explained by the body mass index. Slightly more than a quarter $(26.7 \%)$ of the estimated inequalities in hypertension is explained by socioeconomic factors (paid employment (7.0\%), education (9.3\%) and wealth index (10.4\%)) while sociodemographic factors (female gender (10.5\%), age (4.3\%) and marital status $(0.6 \%)$ ) explained $15.4 \%$ of the observed inequality. Lastly, the regions explained $7.1 \%$ of the estimated inequality with the Central region alone explaining $6.0 \%$ of the observed inequality while individual health behaviour explained only $3.7 \%$ (smoking (2.3\%) and alcohol use (1.4\%)).

Respondents who were middle-aged, unmarried, urban residents, with primary school and higher education, moderately physically active, current alcohol users, overweight and obese and from Nairobi, Western, Central and Eastern regions were mainly concentrated among the poor populations (indicated by the negative concentration indices) and were likely to be hypertensive (indicated by the coefficients) (Table 3).

\section{Discussion}

Our study revealed a pro-rich inequality in hypertension in Kenya, disfavouring poor individuals. The inequality is explained by body mass index, socioeconomic (wealth index, occupation, and education), sociodemographic (gender, age, and marital status) factors, regions and individual health behaviours (current history of alcohol use and smoking). The prevalence of hypertension reported in the current study is similar to previous studies conducted in Kenya [12, 16, 46-48]. Similarly, the high prevalence of hypertension among men and older adults compared to women and younger adults have also been established [12, 16, 46-48].

Similar to other studies in LMICs $[8,29,49,50]$, our findings indicate the presence of inequalities in hypertension disfavouring the poor population. The magnitude of the inequalities in our study $(\mathrm{C}:-0.08)$ is lower compared to that of Iran (C: - 0.15) $[29,50]$ and among rural residents in Bangladesh (C: - 0.20) $[29,50]$ despite an almost similar hypertension prevalence reflecting the varying levels of inequalities. However, our findings differ from the pro-poor inequality in high blood pressure 
Table 2 Respondents' characteristics and prevalence of hypertension by respondents' characteristics

\begin{tabular}{|c|c|c|c|c|c|}
\hline \multirow[t]{2}{*}{ Categories } & \multirow[t]{2}{*}{ Characteristics } & \multicolumn{2}{|c|}{ Sample $(N=4422)$} & \multicolumn{2}{|c|}{ Prevalence of hypertension } \\
\hline & & $\mathrm{n}$ & $\%$ & $\mathrm{n}$ & $\%[95 \% \mathrm{Cl}]$ \\
\hline \multirow[t]{11}{*}{ Sociodemographic variables } & Sex & & & 1280 & $25.8[23.4,28.3]$ \\
\hline & Male & 1761 & 48.6 & 533 & $28.1[24.7,31.8]$ \\
\hline & Female & 2661 & 51.4 & 747 & $23.6[21.2,26.2]$ \\
\hline & Age, years & & & & \\
\hline & $18-29$ & 1472 & 46.3 & 228 & $14.7[12.0,17.9]$ \\
\hline & $30-39$ & 1230 & 23.2 & 275 & $23.1[19.0,27.7]$ \\
\hline & $40-49$ & 780 & 15.5 & 275 & $36.9[31.4,42.8]$ \\
\hline & $50+$ & 940 & 15.0 & 502 & $52.8[48.4,57.2]$ \\
\hline & Marital status & & & & \\
\hline & Not-in-a-union & 1415 & 34.5 & 420 & $22.1[18.7,25.9]$ \\
\hline & In-a-union & 3006 & 65.5 & 860 & $27.7[24.9,30.8]$ \\
\hline \multirow[t]{15}{*}{ Socioeconomic variables } & Education & & & & \\
\hline & No formal & 745 & 12.6 & 215 & $24.5[19.3,30.7]$ \\
\hline & Primary incomplete & 1080 & 23.3 & 289 & $23.3[20.2,26.8]$ \\
\hline & Primary complete & 1398 & 32.7 & 419 & $27.5[23.7,31.7]$ \\
\hline & Secondary+ & 1199 & 31.4 & 357 & $26.3[21.7,31.5]$ \\
\hline & Occupation & & & & \\
\hline & Unemployed/Unpaid & 1849 & 40.2 & 497 & $22.2[19.3,25.5]$ \\
\hline & Self-employment & 1757 & 40.0 & 525 & $26.2[22.9,29.9]$ \\
\hline & Paid employment & 816 & 20.8 & 258 & $31.8[26.1,38.0]$ \\
\hline & Wealth index (quintiles) & & & & \\
\hline & 1 - Poorest & 885 & 23.6 & 297 & $28.2[22.7,34.4]$ \\
\hline & 2 & 884 & 20.3 & 272 & $29.1[24.8,33.8]$ \\
\hline & 3 & 885 & 19.6 & 263 & $24.1[20.0,28.7]$ \\
\hline & 4 & 884 & 18.7 & 237 & $26.4[22.1,31.3]$ \\
\hline & 5 - Richest & 884 & 17.8 & 211 & $20.1[16.6,24.1]$ \\
\hline \multirow[t]{13}{*}{ Health behaviours } & Current smoking & & & & \\
\hline & No & 3916 & 87.5 & 1128 & $25.6[23.4,28.0]$ \\
\hline & Yes & 506 & 12.5 & 152 & $26.9[20.9,33.8]$ \\
\hline & Current alcohol use & & & & \\
\hline & No & 3504 & 74.7 & 971 & $24.0[21.8,26.5]$ \\
\hline & Yes & 911 & 25.3 & 308 & $31.1[27.9,35.8]$ \\
\hline & Fruits $\&$ vegetable intake & & & & \\
\hline & Enough & 576 & 11.2 & 166 & $25.0[20.3,30.4]$ \\
\hline & Not enough & 3822 & 88.8 & 1114 & $25.9[23.3,28.6]$ \\
\hline & Physical activity & & & & \\
\hline & High & 3236 & 75.1 & 927 & $25.6[23.9,28.6]$ \\
\hline & Moderate & 662 & 14.1 & 188 & $25.1[20.2,30.7]$ \\
\hline & Low & 524 & 10.8 & 165 & $27.7[21.2,35.3]$ \\
\hline \multirow[t]{4}{*}{ Metabolic risk factor } & Body mass index & & & & \\
\hline & Normal & 2250 & 56.3 & 568 & $23.2[20.7,25.8]$ \\
\hline & Undernutrition & 683 & 15.8 & 136 & $16.7[13.2,20.8]$ \\
\hline & Overweight & 775 & 16.7 & 286 & $33.4[28.3,38.9]$ \\
\hline
\end{tabular}


Table 2 Respondents' characteristics and prevalence of hypertension by respondents' characteristics (Continued)

\begin{tabular}{|c|c|c|c|c|c|}
\hline \multirow[t]{2}{*}{ Categories } & \multirow[t]{2}{*}{ Characteristics } & \multicolumn{2}{|c|}{ Sample $(N=4422)$} & \multicolumn{2}{|c|}{ Prevalence of hypertension } \\
\hline & & $\mathrm{n}$ & $\%$ & $n$ & $\%[95 \% \mathrm{Cl}]$ \\
\hline & Obese & 550 & 11.2 & 266 & $45.8[40.6,51.1]$ \\
\hline \multirow[t]{12}{*}{ Community variables } & Residence & & & & \\
\hline & Rural & 2268 & 61.4 & 647 & $26.5[23.8,29.4]$ \\
\hline & Urban & 2154 & 38.6 & 633 & $24.7[20.5,29.4]$ \\
\hline & Regions & & & & \\
\hline & Rift Valley & 1325 & 24.6 & 355 & $24.9[21.1,29.1]$ \\
\hline & Eastern & 767 & 14.0 & 258 & $30.3[25.7,35.3]$ \\
\hline & Nyanza & 569 & 12.5 & 149 & $23.9[19.0,29.7]$ \\
\hline & Coast & 533 & 9.3 & 140 & $20.7[14.8,28.2]$ \\
\hline & Central & 507 & 12.4 & 208 & $38.5[30.4,47.3]$ \\
\hline & Western & 408 & 10.3 & 112 & $26.7[23.9,29.7]$ \\
\hline & North Eastern & 250 & 4.9 & 43 & $16.0[9.8,25.0]$ \\
\hline & Nairobi & 63 & 12.1 & 15 & $18.5[11.2,29.1]$ \\
\hline
\end{tabular}

Note: All the percentages are weighted

reported in a study among women of reproductive age in sub-Saharan Africa [14]. The study reported cumulative inequality for sub-Saharan Africa and did not compute country-specific inequalities which could explain the difference. Nevertheless, our study shows the size of inequality to be lower among women than men $(\mathrm{C}$ : $0.05 \mathrm{vs}-0.09$ ) and the hazardous effect of hypertension concentrated among the underprivileged populations who are poor.

Body mass index was the largest independent contributor to the inequality in hypertension explaining about half of the inequality. Our study shows that almost one in three individuals were overweight or obese and had some of the highest prevalence of hypertension. Obesity and overweight are known risk factors for hypertension [28, 34-36] and independently contributed to 23.5 and $9.5 \%$ of the observed inequality. About $40 \%$ of the obese participants in our study belonged to the poorest wealth quintile. Obesity/overweight increases an individual risk of hypertension especially among individual belonging to the poorest group [12, 16, 35]. The high burden of overweight and obesity in Kenya could be attributed to the rapid urbanisation, economic development, and the related unhealthy behaviours such as consumption of energy dense processed food and sedentary lifestyles [51]. As an ecological study in Kenya has

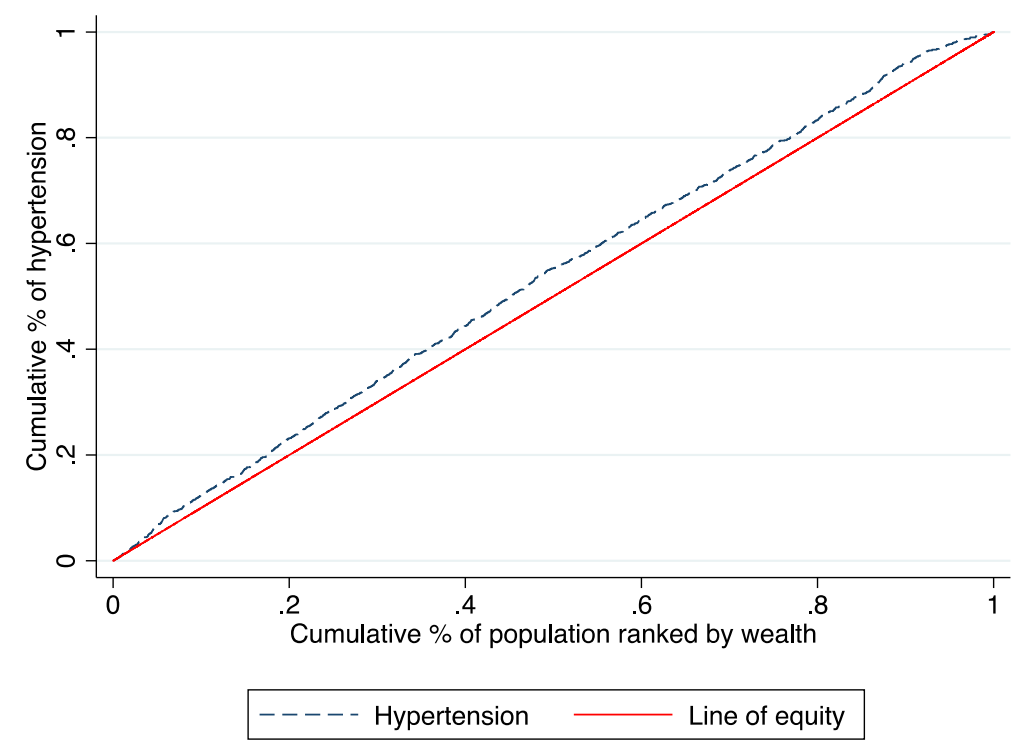

Fig. 1 Concentration curve $(C=-0.081,95 \% \mathrm{Cl}:-0.138,-0.024 ; p=0.005)$ 


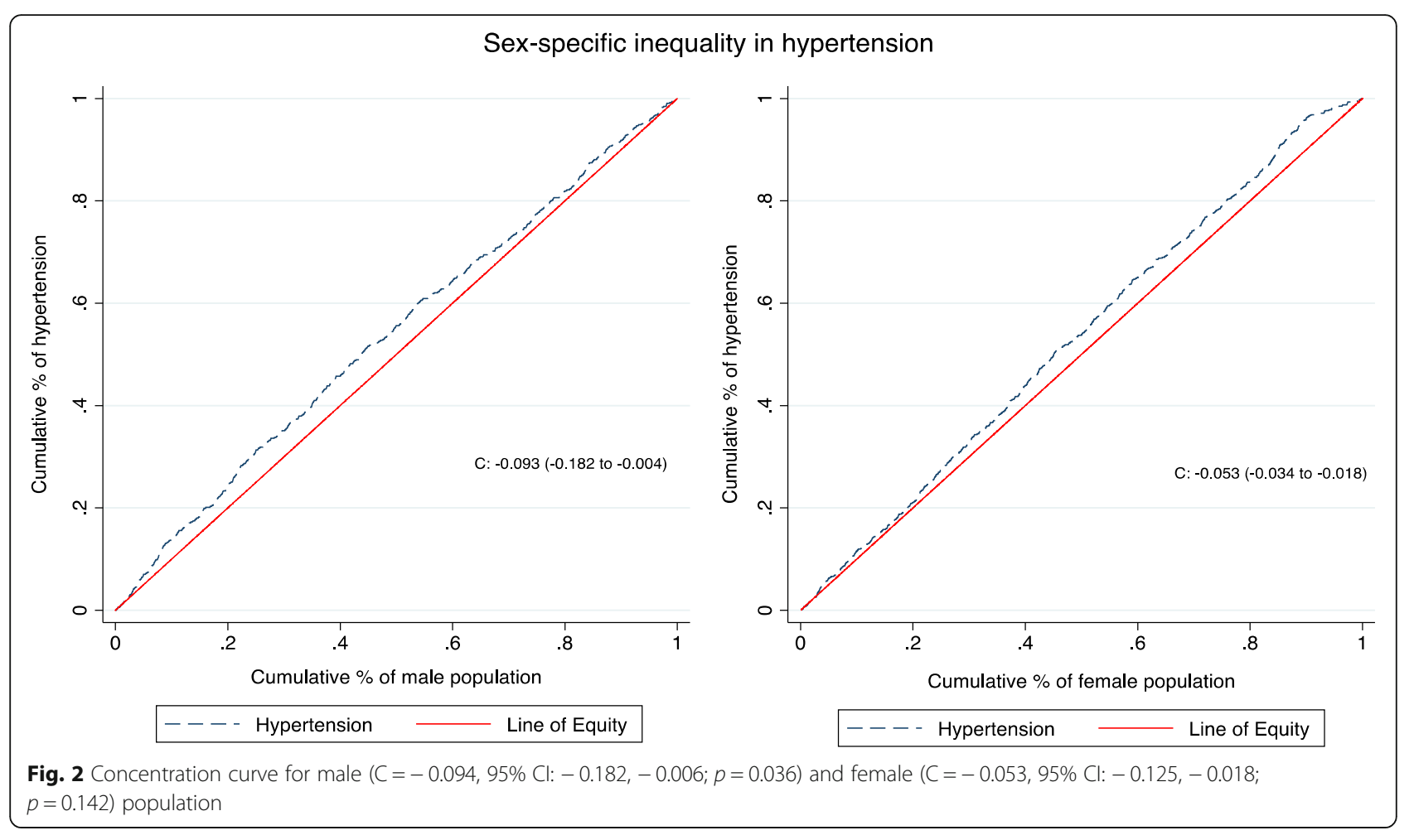

showed, there is a positive association between the rise of NCDs including hypertension in Kenya and the increase in per capita gross domestic product, urbanisation, physical inactivity and consumption of high dense processed foods such as cooking oil and wheat [52].

Surprisingly, undernutrition independently contributed $14.1 \%$ of the observed inequality, which could reflect the high prevalence of hypertension (16.7\%) among the $16 \%$ of our study population who were undernourished. High prevalence of hypertension has previously been reported among undernourished individuals [53]. We hypothesise that the life course approach showing the relationship between childhood/adulthood malnutrition and hypertension could help explain this finding. Malnutrition limits renal development resulting in kidney malfunction in adulthood and eventually hypertension [54, 55]. However, we studied adult individuals some of whom were already malnourished and could not ascertain the timing of the occurrence of malnutrition and any causal linkage to their hypertension. This calls for further evaluation to establish the causal relationship between adult undernutrition and hypertension with a focus on the poor populations.

Occupation, education, and wealth index are the socioeconomic factors contributing to slightly more than a quarter of the observed inequalities in hypertension. Similarly, these factors also explained inequality in hypertension in Iran [29]. In this study, individuals in formal paid employment were more concentrated among the poor and had a relatively high prevalence of hypertension compared to the unemployed and selfemployed individuals. In Kenya, studies have shown that casual workers and individuals on formal employment have increased odds of hypertension [12] which could be attributed to sedentary lifestyle. Our findings also revealed that individuals with low education level (incomplete or complete primary educations) were more likely to be hypertensive and poor. Low education level is associated with the risk of developing hypertension $[16,27$, 28]. However, among older adults in Kenya, education was found not be associated with hypertension [13]. Despite this, educated individuals have a better awareness of hypertension and its preventive strategies compared to the uneducated $[10,11]$. Wealth index explained one-tenth of the observed inequality in hypertension with almost equal individual contribution from both the richest and poorer wealth quintiles. Our findings show a high prevalence of hypertension among individuals in the poorest wealth quintile, which is inconsistent with previous studies [12, 14]. For example, one of the studies in the urban slums in Nairobi Kenya found that individuals in the richest wealth quintile had the highest prevalence of hypertension and were at an increased odd of being hypertensive [12]. This could be due to the differences in study population. However, we hypothesize the poorest individuals faces several financial barriers, which hinder access to health services for control and treatment of hypertension [56] due to huge 
Table 3 Summary of decomposition analysis

\begin{tabular}{|c|c|c|c|c|c|c|c|}
\hline Category & Characteristics & Coeff. & Elasticity & $C$ & Cont. to C & $\%$ & Adjusted $\%^{a}$ \\
\hline \multirow[t]{6}{*}{ Sociodemographic variables } & Female gender (Ref: male) & -0.057 & -0.132 & 0.122 & -0.016 & 20.1 & 10.5 \\
\hline & Married (Ref: unmarried) & 0.009 & 0.024 & -0.040 & -0.001 & 1.2 & 0.6 \\
\hline & Age, years (Ref: 18-29 years) & & & & & & 4.3 \\
\hline & $30-39$ & 0.071 & 0.077 & -0.004 & -0.0003 & 0.4 & 0.2 \\
\hline & $40-49$ & 0.191 & 0.131 & -0.049 & -0.006 & 7.9 & 4.1 \\
\hline & $50+$ & 0.386 & 0.318 & 0.123 & 0.039 & -48.8 & \\
\hline \multirow[t]{12}{*}{ Socioeconomic variables } & Education (Ref: No formal) & & & & & & 9.4 \\
\hline & Primary incomplete & -0.015 & -0.014 & 0.255 & -0.004 & 4.7 & 2.5 \\
\hline & Primary complete & 0.045 & 0.055 & -0.117 & -0.006 & 8.0 & 4.2 \\
\hline & Secondary+ & 0.007 & 0.007 & -0.594 & -0.004 & 5.1 & 2.7 \\
\hline & Occupation (Ref: Unemployed) & & & & & & \\
\hline & Self-employment & -0.001 & -0.002 & -0.033 & 0.0001 & -0.1 & \\
\hline & Paid employment & 0.031 & 0.022 & -0.475 & -0.011 & 13.3 & 7.0 \\
\hline & Wealth Index (Ref: Poorest) & & & & & -0.8 & 11.7 \\
\hline & Poorer & 0.023 & 0.018 & 0.499 & 0.009 & 11.2 & 5.9 \\
\hline & Middle & -0.018 & -0.014 & 0.0002 & 0.000 & 0.0 & \\
\hline & Richer & 0.008 & 0.023 & -0.500 & 0.003 & -4.0 & \\
\hline & Richest & -0.009 & 0.007 & -1.000 & -0.007 & 8.5 & 4.5 \\
\hline \multirow[t]{6}{*}{ Health behaviours } & Current smokers (Ref: No) & -0.028 & -0.013 & 0.281 & -0.004 & 4.4 & 2.3 \\
\hline & Current alcohol use (Ref: No) & 0.068 & 0.054 & -0.038 & -0.002 & 2.6 & 1.4 \\
\hline & Insufficient fruits/vegetable intake & 0.024 & 0.080 & 0.023 & 0.002 & -2.3 & \\
\hline & Physical activity (Ref: High) & & & & & & \\
\hline & Moderate & -0.009 & -0.005 & -0.156 & 0.001 & -1.0 & \\
\hline & Low & 0.032 & 0.015 & 0.084 & 0.001 & -1.5 & \\
\hline \multirow[t]{4}{*}{ Metabolic risk factor } & Body mass index (Ref: Normal) & & & & & & 47.1 \\
\hline & Undernutrition & -0.089 & -0.055 & 0.386 & -0.021 & 26.8 & 14.1 \\
\hline & Overweight & 0.090 & 0.064 & -0.227 & -0.015 & 18.1 & 9.5 \\
\hline & Obese & 0.200 & 0.100 & -0.359 & -0.036 & 44.9 & 23.5 \\
\hline \multirow[t]{13}{*}{ Geographical factors } & Urban residence (Ref: rural) & -0.013 & -0.024 & -0.388 & 0.009 & -11.6 & \\
\hline & Regions (Ref: Rift Valley) & & & & & 11.6 & 7.1 \\
\hline & Eastern & 0.021 & 0.014 & -0.011 & -0.0002 & 0.2 & 0.1 \\
\hline & Nyanza & -0.016 & -0.008 & 0.076 & -0.006 & 0.7 & 0.4 \\
\hline & Coast & -0.050 & -0.023 & 0.013 & -0.0003 & 0.4 & 0.2 \\
\hline & Central & 0.063 & 0.028 & -0.325 & -0.009 & 11.4 & 6.0 \\
\hline & Western & -0.008 & -0.003 & -0.043 & 0.0001 & -0.2 & \\
\hline & North Eastern & -0.005 & -0.001 & 0.644 & -0.007 & 0.8 & 0.4 \\
\hline & Nairobi & -0.067 & -0.004 & -0.541 & 0.002 & -2.5 & \\
\hline & Concentration index & & & -0.081 & & & \\
\hline & Standard error & & & 0.029 & & & \\
\hline & Residuals & & & -0.0002 & & & \\
\hline & $95 \% \mathrm{Cl}$ & & -0.138 to & 0.024 & & & \\
\hline
\end{tabular}

Bold: $p<0.05$. Coeff. coefficient (marginal effects); C concentration index; Cont to C: contribution to concentration index; \% percentage contribution; Ref reference category; SE standard error; ${ }^{\mathbf{a}}$ The absolute contribution of each determinant was divided by the total explained portion that make contributions to the same direction of the concentration index. 
out of pocket expenditure [6,57]. In addition, despite the hypertension screening and early diagnosis being key in averting hypertension, it is likely that individuals in the richest wealth quintile are screened more for high blood pressure than the poorest individuals. Among urban poor populations in Kenya, increased wealth may contribute to unhealthy behaviours such as consumption of energy dense processed food and sedentary lifestyles [12].

Socio-demographic factors explained about $15 \%$ of the observed inequality. Specifically, gender had a substantial contribution to the inequality with men having a significantly higher prevalence of inequalities in hypertension than women. Previous studies have observed gender disparities in hypertension [26-28], which have been attributed to biological [58] and health behavioural factors [59]. In this study, a further gender-specific decomposition shows that the differences in body mass index, education, employment, and the region could explain the gender disparities in hypertension (Supplementary Table 2). Age, especially 40-49 years also contributed to the observed inequality in hypertension. Adults aged 35 years and above have increased the risk of hypertension in Kenya [12], which is supported by our finding that a third of these adults are hypertensive. Overall, older adults in Kenya have increased odds of multiple NCD risk factors [60] hence increased risk of hypertension. Moreover, the current study shows substantial inequality in hypertension for the older and poor population. These findings call for gender-focused approaches in prevention, treatment, and control of hypertension in Kenya.

Regional differences mainly attributed to Central region contributed to $7.1 \%$ of the observed inequalities in hypertension. The central region had the highest prevalence of hypertension. Its main inhabitants, the Kikuyu ethnic groups, has high prevalence hypertension [61] and cardiometabolic markers [60]. It is also one of the most unequal regions in Kenya [62] with a large population of older adults (7\%) and high prevalence of alcohol use and smoking. At local level, the high prevalence of hypertension has been speculated to results from poor dietary practices such as high consumption of carbohydrates and sedentary lifestyles [63] and poor awareness on hypertension [64].

Behavioural risk factors contributing to the inequalities in hypertension were current history of smoking and alcohol use. Alcohol use and smoking are associated with increased risk of hypertension [27, 34, 65, 66]. The prevalence of smoking [14, 31,32] and alcohol use [14, 33] was high among individuals in the poorest wealth quintile. These poor individuals are also likely to be hypertensive hence contribute to hypertension inequality in Kenya. To address the challenges of smoking and alcohol use, Kenya has through legislation banned advertisement of tobacco and its products, limited the number of cigarettes sold, criminalised the sale of illegal alcohol and increased taxes on alcohol and tobacco and its products.

\section{Strengths and limitations}

To our knowledge, this is the first study in Kenya quantifying and explaining the inequalities in hypertension. One of the strengths of the study is the use of data collected based on the standardised WHO STEPwise approach from a large nationally representative sample making our finding generalisable to Kenya and comparable to studies using similar approach. Also, the study variables included explained the observed inequalities with minimal residual. However, the study had some limitations. First, the data used was crosssectional and hence causal inference could not be made. Second, the blood pressure measurements were taken in one visit which could have resulted in an overestimation of the prevalence. Third, there was a potential for recall bias in self-reported variables such as physical activity, tobacco and alcohol use and fruits and vegetable consumption, which may have over- or underestimated their prevalence. Fourth, the study included some explanatory variables that are closely related such as wealth, education, and occupation in the decomposition analysis. Inclusion of all these variables may have resulted in the underestimation of the full effect of either of the variables and may have ignored the potential causal hierarchy among the variables, for example, education being a driver for wealth and occupation.

\section{Conclusion}

The present study shows pro-rich inequality in hypertension, which is mainly explained by individual health behaviour, socioeconomic and sociodemographic factors. These findings are particularly important considering that more than half of the Kenyan population, aged 1869 years are pre-hypertensive [48, 67]. We call for gender- and equity-focused interventions, as proposed in the national strategy for non-communicable diseases to curb the rising burden of hypertension and address the inequalities in hypertension. Importantly, the study findings highlight the significant contribution of obesity/ overweight in hypertension inequalities, which calls for further research and investments in measures to curb obesity such as taxes on highly processed foods, sweetened beverages and promoting physical activity.

\section{Supplementary information}

The online version contains supplementary material available at https://doi. org/10.1186/s12939-020-01321-1.

Additional file 1: Table S1. Variables included in the calculation of wealth index. Table S2. Summary of decomposition analysis for male and female. 


\section{Abbreviations}

C: Concentration index; MET: Metabolic Equivalent of Task; NCDs: Noncommunicable diseases; US: United States; WHO: World Health Organization; SE: Standard error

\section{Acknowledgements}

We are grateful to the Kenya National Bureau of Statistics for access to the dataset and Mary Wairimu Gatimu for helping in the preparation of the initial draft.

\section{Authors' contributions}

SMG conceptualized the study and performed data analysis. SMG and JWT wrote, reviewed, and approved the manuscript.

\section{Funding}

This work did not receive any funding.

\section{Availability of data and materials}

Data used in this study can be accessed based on the Kenya National Bureau of Statistics data access agreement on http://statistics.knbs.or.ke/ nada/index.php/catalog/90

\section{Ethics approval and consent to participate}

The study used secondary data from the Kenya STEPwise survey for noncommunicable disease risk factors 2015 that was approved by the Kenya Medical Research Institute Ethics Review Committee (SSC No. 2607) and the respondents provided written consents before the survey.

\section{Consent for publication}

Not applicable.

\section{Competing interests}

The authors declare that they have no competing interest.

\section{Author details}

${ }^{1}$ School of Economics, University of Nairobi, Nairobi, Kenya. ${ }^{2}$ Medical Department, Mkinga District Council, Tanga, Tanzania.

Received: 20 July 2020 Accepted: 9 November 2020

\section{Published online: 02 December 2020}

\section{References}

1. Mills KT, Stefanescu A, He J. The global epidemiology of hypertension. Nat Rev Nephrol. 2020;16:223-37.

2. World Health Organization. Global action plan for the prevention and control of noncommunicable diseases 2013-2020. Geneva: World Health Organization; 2013.

3. Kenya National Bureau of Statistics. World health organisation, Ministry of Health: Kenya STEPwise survey for non-communicable diseases risk factors 2015 report. Nairobi: Kenya National Bureau of Statistics; 2015.

4. Ogola E, Okello FO, Macgregor-skinner E, Jimenez J, Yonga G. [OP.3C.03] blood pressure screeningresults from healthy heart Africa: screening locations, participant characteristics, and hypertension classification in Kenya. J Hypertens. 2017;35:e30-1.

5. van de Vijver SJ, Oti SO, Agyemang C, Gomez GB, Kyobutungi C. Prevalence, awareness, treatment and control of hypertension among slum dwellers in Nairobi, Kenya. J Hypertens. 2013;31:1018-24.

6. Oyando R, Njoroge M, Nguhiu P, Kirui F, Mbui J, Sigilai A, Bukania Z, Obala A, Munge K, Etyang A, Barasa E. Patient costs of hypertension care in public health care facilities in Kenya. Int J Health Plann Manag. 2019;34:e1166-78.

7. Cha SH, Park HS, Cho HJ. Socioeconomic disparities in prevalence, treatment, and control of hypertension in middle-aged Koreans. J Epidemiol. 2012:JE20110132.

8. Palafox B, Mckee M, Balabanova D, Alhabib KF, Avezum AJ, Bahonar A Ismail N, Chifamba J, Chow CK, Corsi DJ, et al. Wealth and cardiovascular health : a cross-sectional study of wealth-related inequalities in the awareness, treatment and control of hypertension in high- , middle- and low-income countries. Int J Equity Health. 2016;15:15-7.

9. Vellakkal S, Millett C, Basu S, Khan Z, Aitsi-Selmi A, Stuckler D, Ebrahim S. Are estimates of socioeconomic inequalities in chronic disease artefactually narrowed by self-reported measures of prevalence in low-income and middle-income countries? Findings from the WHO-SAGE survey. J Epidemiol Community Health. 2015;69:218-25.

10. Leng B, Jin Y, Li G, Chen L, Jin N. Socioeconomic status and hypertension: a meta-analysis. J Hypertens. 2015:33:221-9.

11. Grotto I, Huerta M, Sharabi Y. Hypertension and socioeconomic status. Curr Opin Cardiol. 2008;23:335-9.

12. Olack B, Wabwire-Mangen F, Smeeth L, Montgomery JM, Kiwanuka N, Breiman RF. Risk factors of hypertension among adults aged 35-64 years living in an urban slum Nairobi, Kenya. BMC Public Health. 2015;15:1251.

13. Ploubidis GB, Mathenge W, De Stavola B, Grundy E, Foster A, Kuper H. Socioeconomic position and later life prevalence of hypertension, diabetes and visual impairment in Nakuru, Kenya. Int J Public Health. 2013;58:133-41.

14. Yaya S, Uthman OA, Ekholuenetale M, Bishwajit G. Socioeconomic inequalities in the risk factors of noncommunicable diseases among women of reproductive age in sub-saharan Africa: a multi-country analysis of survey data. Front Public Health. 2018;6:307.

15. Fateh M, Emamian MH, Asgari F, Alami A, Fotouhi A. Socioeconomic inequality in hypertension in Iran. J Hypertens. 2014;32:1782-8.

16. Joshi MD, Ayah R, Njau EK, Wanjiru R, Kayima JK, Njeru EK, Mutai KK. Prevalence of hypertension and associated cardiovascular risk factors in an urban slum in Nairobi, Kenya: a population-based survey. BMC Public Health. 2014;14:1177.

17. Ministry of Health. Kenya National Strategy for the Prevention and Control of Non-Communicable Diseases (NCDs) 2015-2020. Nairobi: Ministry of Health, Kenya; 2015.

18. Kenya National Bureau of Statistics: Kenya - Kenya Stepwise Survey for Non Communicable Diseases Risk Factors 2015. Statistics KNBo ed., Version 1.0 (May 2016) edition. Nairobi. Kenya; 2015.

19. Chobanian AV, Bakris GL, Black HR, Cushman WC, Green LA, Izzo JL Jr, Jones DW, Materson BJ, Oparil S, Wright JT Jr, et al. The seventh report of the joint National Committee on prevention, detection, evaluation, and treatment of high blood pressure: the JNC 7 report. JAMA. 2003;289:2560-72.

20. Ministry of Health. Kenya National Guidelines for Cardiovascular Diseases Management. Nairobi: Ministry of Health, Division of Non-Communicable Diseases; 2018.

21. Vyas S, Kumaranayake L. Constructing socio-economic status indices: how to use principal components analysis. Health Policy Plan. 2006;21:459-68.

22. Rutstein SO. Steps to constructing the new DHS wealth index. Rockville, MD: ICF International; 2015.

23. Rutstein SO, Staveteig S. Making the demographic and health surveys wealth index comparable; 2014.

24. Howe LD, Hargreaves JR, Huttly SR. Issues in the construction of wealth indices for the measurement of socio-economic position in low-income countries. Emerg Themes Epidemiol. 2008;5:3.

25. Mohamed SF, Mutua MK, Wamai R, Wekesah F, Haregu T, Juma P, Nyanjau $L$, Kyobutungi C, Ogola E. Prevalence, awareness, treatment and control of hypertension and their determinants: results from a national survey in Kenya. BMC Public Health. 2018;18:1219.

26. Ba HO, Camara Y, Menta I, Sangare I, Sidibe N, Diall IB, Coulibaly S, Keita MA Millogo GRC. Hypertension and associated factors in rural and urban areas Mali: data from the STEP 2013 survey. Int J Hypertens. 2018;2018:6959165.

27. Bosu WK, Aheto JMK, Zucchelli E, Reilly ST. Determinants of systemic hypertension in older adults in Africa: a systematic review. BMC Cardiovasc Disord. 2019;19:173.

28. Sarki AM, Nduka CU, Stranges S, Kandala NB, Uthman OA. Prevalence of hypertension in low- and middle-income countries: a systematic review and meta-analysis. Medicine (Baltimore). 2015;94:e1959.

29. Veisani Y, Jenabi E, Nematollahi S, Delpisheh A, Khazaei S. The role of socioeconomic inequality in the prevalence of hypertension in adults. Tabriz University of Medical Sciences. 2019;11:116-20.

30. World Health Organisation. Global physical activity questionnaire (GPAQ): analysis guide. Geneva: World Health Organization; 2009.

31. Dickson KS, Ahinkorah BO. Understanding tobacco use and socioeconomic inequalities among men in. BMC Archives of Public Health. 2017:1-8.

32. Irazola V, Santero M, Melendi S, Herna A. Socio-economic inequalities in smoking prevalence and involuntary exposure to tobacco smoke in Argentina : Analysis of three cross-sectional nationally representative surveys in 2005, 2009 and 2013. PLoS One. 2019:1-16.

33. Lawana N. Decomposing socioeconomic inequalities in alcohol use by men living in south African urban informal settlements. BMC Public Health. 2018; 18:1-9. 
34. Ondimu DO, Kikuvi GM, Otieno WN. Risk factors for hypertension among young adults (18-35) years attending in Tenwek Mission hospital, Bomet County, Kenya in 2018. Pan Afr Med J. 2019;33:210.

35. Akpa OM, Made F, Ojo A, Ovbiagele B, Adu D, Motala AA, Mayosi BM, Adebamowo SN, Engel ME, Tayo B, et al. Epidemiology / population science regional patterns and association between obesity and hypertension in Africa evidence from the H3Africa CHAIR study. Obesity and Hypertension in Africa. 2020:1167-78.

36. Oladimeji AM, Fawole O, Nguku P, Nsubuga P. Prevalence and factors associated with hypertension and obesity among civil servants in Kaduna, Kaduna State, June 2012. PanAfrican Medical Journal. 2014;18:1-5.

37. O'Donnell O, Van Doorslaer E, Wagstaff A, Lindelow M. Analyzing health equity using household survey data: a guide to techniques and their implementation. 2008. Washington, DC: The World Bank; 2008. p. 220.

38. Wagstaff $\mathrm{A}$. The concentration index of a binary outcome revisited. Health Econ. 2011;20:1155-60

39. Wagstaff A. Correcting the concentration index: a comment. J Health Econ. 2009;28:516-20 author reply 521-514.

40. Wagstaff A, Doorslaer VE, Watanabe N. On decomposing the causes of health sector inequalities with an application to malnutrition inequalities in Vietnam. The World Bank; 2001.

41. Amroussia N, Gustafsson PE, Mosquera PA. Explaining mental health inequalities in northern Sweden: a decomposition analysis. Glob Health Action. 2017;10:1305814

42. Gonzalo-Almorox E, Urbanos-Garrido RM. Decomposing socio-economic inequalities in leisure-time physical inactivity: the case of Spanish children. Int J Equity Health. 2016;15:106.

43. Heckley G, Gerdtham UG, Kjellsson G. A general method for decomposing the causes of socioeconomic inequality in health. J Health Econ. 2016;48: 89-106.

44. Lai S, Shen C, Yang X, Zhang X, Xu Y, Li Q, Gao J, Zhou Z. Socioeconomic inequalities in the prevalence of chronic diseases and preventive care among adults aged 45 and older in Shaanxi Province, China. BMC Public Health. 2019;19:1460.

45. Mutyambizi C, Booysen F, Stokes A, Pavlova M, Groot W. Lifestyle and socioeconomic inequalities in diabetes prevalence in South Africa: a decomposition analysis. PLoS One. 2019;14:e0211208.

46. Vusirikala A, Wekesah F, Kyobutungi C, Oyebode O. Assessment of cardiovascular risk in a slum population in Kenya: use of World Health Organisation/International Society of Hypertension (WHO/ISH) risk prediction charts - secondary analyses of a household survey. BMJ Open. 2019:9:e029304

47. Gomez-Olive FX, Ali SA, Made F, Kyobutungi C, Nonterah E, Micklesfield L, Alberts M, Boua R, Hazelhurst S, Debpuur C, et al. Regional and sex differences in the prevalence and awareness of hypertension: an H3Africa AWI-gen study across 6 sites in sub-Saharan Africa. Glob Heart. 2017;12:81-90.

48. Onyango MJ, Kombe I, Nyamongo DS, Mwangi M. A study to determine the prevalence and factors associated with hypertension among employees working at a call Centre Nairobi Kenya. Pan Afr Med J. 2017;27:178.

49. Price AJ, Crampin AC, Amberbir A, Kayuni-chihana N, Musicha C, Tafatatha T, Branson K, Lawlor DA, Mwaiyeghele E, Nkhwazi L, et al. Prevalence of obesity, hypertension, and diabetes, and cascade of care in sub-Saharan Africa : a cross-sectional, population-based study in rural and urban Malawi. Lancet Diabetes Endocrinology. 2018;6:208-22.

50. Biswas T, Islam MS, Linton N, Rawal LB. Socio-economic inequality of chronic non-communicable diseases in Bangladesh. PLoS One. 2016;11: e0167140.

51. Steyn NP, Nel JH, Parker WA, Ayah R, Mbithe D. Dietary, social, and environmental determinants of obesity in Kenyan women. Scand J Public Health. 2011;39:88-97.

52. Onyango EM, Onyango BM. The rise of noncommunicable diseases in Kenya: an examination of the time trends and contribution of the changes in diet and physical inactivity. J Epidemiol Glob Health. 2018:8:1-7.

53. Wang Z, Li C, Yang Z, Zou Z, Ma J. Infant exposure to Chinese famine increased the risk of hypertension in adulthood : results from the China health and retirement longitudinal study. BMC Public Health. 2016:1-11.

54. Mackenzie HS, Uk M, Brenner BM. Fewer nephrons at birth : a missing link in the etiology of essential hypertension? Am J Kidney Dis. 1995:26:91-6.

55. Gurusinghe S, Brown RD, Cai X, Samuel CS, Ricardo SD, Thomas MC, Kett MM. Does a nephron deficit exacerbate the renal and cardiovascular effects of obesity ? PLoS One. 2013;8.
56. Rockers PC, Laing RO, Wirtz VJ. Equity in access to non-communicable disease medicines: a cross-sectional study in Kenya. BMJ Glob Health. 2018; 3:e000828.

57. Karinja M, Pillai G, Schlienger R, Tanner M, Ogutu B. Care-seeking dynamics among patients with diabetes mellitus and hypertension in selected rural settings in Kenya. Int J Environ Res Public Health. 2019;16.

58. Song J-J, Ma Z, Wang J, Chen L-X, Zhong J-C. Gender Differences in Hypertension. J Cardiovasc Transl Res. 2020;13:47-54.

59. Everett B, Zajacova A. Gender differences in hypertension and hypertension awareness among young adults. Biodemography Soc Biol. 2015;61:1-17.

60. Wekesah FM, Nyanjau L, Kibachio J, Mutua MK, Mohamed SF, Grobbee DE, Klipstein-Grobusch K, Ngaruiya C, Haregu TN, Asiki G, Kyobutungi CK. Individual and household level factors associated with presence of multiple non-communicable disease risk factors in Kenyan adults. BMC Public Health. 2018;18:1220.

61. Mathenge W, Foster A, Kuper H. Urbanization, ethnicity and cardiovascular risk in a population in transition in Nakuru, Kenya: a population-based survey. BMC Public Health. 2010;10:569.

62. Stiftung FE. Regional Disparities and Marginalization in Kenya. Nairobi: Elite PrePress; 2012.

63. Mugo I. Nyeri's chronic disease burden. In Daily Nation. Nation Media Group: Nairobi, Kenya; 2018.

64. Freiberg MAT, Onyango NO, Ashbaugh SJ, Mehta K. Chronic diseases in Nyeri, Kenya: a study of knowledge and perceptions. Healthcare in LowResource Settings. 2016;4.

65. Belue R, Okoror TA, Iwelunmor J, Taylor KD, Degboe AN, Agyemang C, Ogedegbe G. Globalization and health an overview of cardiovascular risk factor burden in sub-Saharan African countries : a socio-cultural perspective. BMC Globalization and Health. 2009;12:1-12.

66. Hulzebosch A, van de Vijver S, Oti SO, Egondi T, Kyobutungi C. Profile of people with hypertension in Nairobi's slums: a descriptive study. Glob Health. 2015;11:26.

67. Mecha JO, Kubo EN, Odhiambo CO, Kinoti FG, Njau K, Yonga G, Ogola EN. Burden of prehypertension among adults in Kenya: a retrospective analysis of findings from the healthy heart Africa (HHA) Programme. BMC Public Health. 2020;20:281.

\section{Publisher's Note}

Springer Nature remains neutral with regard to jurisdictional claims in published maps and institutional affiliations.
Ready to submit your research? Choose BMC and benefit from:

- fast, convenient online submission

- thorough peer review by experienced researchers in your field

- rapid publication on acceptance

- support for research data, including large and complex data types

- gold Open Access which fosters wider collaboration and increased citations

- maximum visibility for your research: over $100 \mathrm{M}$ website views per year

At $\mathrm{BMC}$, research is always in progress.

Learn more biomedcentral.com/submissions 